\title{
A Proteomic Analysis Reveals the Interaction of GluK1 Ionotropic Kainate Receptor Subunits with Go Proteins
}

\author{
ODizabela Rutkowska-Wlodarczyk, ${ }^{1}$ M. Isabel Aller, ${ }^{1}$ Sergio Valbuena, ${ }^{1}$ Jean-Charles Bologna, ${ }^{2}$ Laurent Prézeau, ${ }^{2}$ \\ and Juan Lerma ${ }^{1}$ \\ ${ }^{1}$ Instituto de Neurociencias, Consejo Superior de Investigaciones Científicas, Universidad Miguel Hernández, 03550 San Juan de Alicante, Spain, and \\ ${ }^{2}$ Institut de Génomique Fonctionnelle, Centre National de la Recherche Scientifique, Institut National de la Santé et de la Recherche Médicale, 34094 \\ Montpellier cedex 5, France
}

\begin{abstract}
Kainate receptors (KARs) are found ubiquitously in the CNS and are present presynaptically and postsynaptically regulating synaptic transmission and excitability. Functional studies have proven that KARs act as ion channels as well as potentially activating G-proteins, thus indicating the existance of a dual signaling system for KARs. Nevertheless, it is not clear how these ion channels activate G-proteins and which of the KAR subunits is involved. Here we performed a proteomic analysis to define proteins that interact with the C-terminal domain of GluK1 and we identified a variety of proteins with many different functions, including a Go $\alpha$ subunit. These interactions were verified through distinct in vitro and in vivo assays, and the activation of the Go protein by GluK1 was validated in bioluminescence resonance energy transfer experiments, while the specificity of this association was confirmed in GluK1-deficient mice. These data reveal components of the KAR interactome, and they show that GluK1 and Go proteins are natural partners, accounting for the metabotropic effects of KARs.
\end{abstract}

Key words: GluK1; Go protein; kainate receptors; metabotropic; noncanonical; proteomics

\section{Introduction}

Our understanding of kainate receptors (KARs), their function, and their impact on brain activity lags behind that of such other members of the glutamate receptor family as the AMPA receptors (AMPARs) and the NMDA receptors (NMDARs). KARs, AMPARs, and NMDARs are the most important members of the ionotropic receptor family, although there is evidence that they play their roles through unexpected noncanonical mechanisms (Wang et al., 1997; Rodríguez-Moreno and Lerma, 1998; Cunha et al., 1999; Nabavi et al., 2013). In this regard, perhaps the best documented case is that of the KAR. The noncanonical mode of KAR signaling was first described in the hippocampus (Rodríguez-Moreno and Lerma, 1998), where the inhibition of GABA release was found to be sensitive to pertussis toxin and

\footnotetext{
Received Dec. 13, 2014; revised Feb. 2, 2015; accepted Feb. 18, 2015.

Author contributions: J.L. designed research; I.R.-W., M.I.A., S.V., and J.-C.B. performed research; L.P. contributed unpublished reagents/analytic tools; I.R.-W., M.I.A., and S.V. analyzed data; J.L. wrote the paper.

This work was supported by grants to J.L. from the Spanish Ministry of Science and Innovation (BFU2006-07138 and BFU2011-24084), CONSOLIDER (CSD2007-00023), and Prometeo/2011/086, and by the EU FP7 Capacities Project BI0-IMAGINE (Grant Agreement No. 264173). We thank C. Mulle and J. Marshall for plasmids, M. Llinares for excellent technical assistance, Esther Picó for collaborating on parts of the proteomic analysis, and Antonio Javier Caler for technical assistance with the FACS. We also thank the Laboratory of Mass Spectrometry (Institute of Biochemistry and Biophysics, Polish Academy of Sciences, Warsaw) for recording the MS spectra and participating in the proteomics analysis. The Instituto de Neurociencias is a "Severo 0choa" Center of Excellence.

The authors declare no competing financial interests.

Correspondence should be addressed to Juan Lerma, Instituto de Neurociencias, CSIC-UMH, 03550 San Juan de Alicante, Spain. E-mail: jlerma@umh.es.

I. Rutkowska-Wlodarczyk's present address: Laboratory of Neurobiology, Nencki Institute, 3 Pasteur Str., $02-093$ Warsaw, Poland.

DOI:10.1523/JNEUROSCI.5059-14.2015

Copyright $\odot 2015$ the authors $\quad 0270-6474 / 15 / 355171-09 \$ 15.00 / 0$
}

inhibitors of PKC. Noncanonical metabotropic signaling was subsequently firmly established in dorsal root ganglion cells (DRGs), in which the action of KARs triggers the release of $\mathrm{Ca}^{2+}$ from intracellular stores through the activation of a G-protein and phospholipase-C (PLC; Rozas et al., 2003). Further work has extended the concept of KAR coupling to G-proteins (Cunha et al., 2000; Rodríguez-Moreno et al., 2000; Melyan et al., 2002; Lerma and Marques, 2013), something that is difficult to reconcile with the typical molecular structure of these ion channels. Accordingly, attempts to explain how an ion channel interacts with a G-protein have fuelled the search for proteins that could interact with KARs and participate in this function.

Technical progress in proteomics has facilitated the identification of protein partners that interact with glutamate receptors, which has led to evidence that such proteins may determine critical functional properties and influence the trafficking of KARs (Palacios-Filardo et al., 2014). Several proteins have been identified that interact with KARs, particularly with their GluK2 subunits (Coussen and Mulle, 2006; Martin et al., 2007; Wilkinson et al., 2008; Tomita and Castillo, 2012), and to a lesser extent with GluK1 (Hirbec et al., 2003) and GluK5 subunits (Vivithanaporn et al., 2006; Selak et al., 2009; Marques et al., 2013). Indeed, PICK1 (protein interacting with C-kinase 1), SNAP25 (synaptosomal-associated protein of $25 \mathrm{kDa}$ ), GRIP (glutamate receptor-interacting protein), SUMO-1 (small ubiquitin-related modifier-1), calcineurin, VILIP (visinin-like protein), Profilin II, and Neto 1 and 2 are among those proteins now known to interact with KAR subunits (for review, see Lerma and Marques, 2013).

With the aim of identifying further KAR-interacting proteins that might account for noncanonical KAR signaling, we per- 
formed a proteomic analysis on the GluK1 subunit. This subunit was selected as it seems to be required to mediate endogenous noncanonical signaling in DRGs (Rozas et al., 2003) and it is sufficient to reconstitute this kind of signaling in a heterologous neuroblastoma system (Rivera et al., 2007). The results of this study revealed that the GluK1 subunit might interact with signal transduction, with presynaptic and cytoskeletal/structural proteins, and with proteins involved in vesicle trafficking. Furthermore, the $\alpha$ subunit of the o-class guanine nucleotide binding proteins $(\mathrm{G} \alpha \mathrm{o})$ subunit was also found to interact with GluK1, and functional assays revealed that GluK1 can activate the Go heterotrimeric protein. Therefore, these data reveal distinct elements of the KAR interactome and they provide evidence that GluK1 is the most likely candidate to activate Go proteins, accounting for the reported metabotropic actions of KARs.

\section{Materials and Methods}

All the procedures for the handling and killing of animals used in this study conformed with the European Commission guidelines (2010/63/ EU) governing the use of experimental animals, and they were supervised by the veterinary officer at the Instituto de Neurociencias (Alicante).

Preparation of mouse brain homogenate. A brain homogenate was prepared by centrifugation as described previously (Gray and Whittaker, 1962). Briefly, brain tissue isolated from 21-25 postnatal day male and female C57 mice was homogenized in $0.32 \mathrm{~m}$ sucrose prepared in $4 \mathrm{~mm}$ HEPES KOH, pH 7.0, 1 mM EGTA, 0.1 mM EDTA, and a protease inhibitor mixture (Roche Diagnostics). The homogenate was centrifuged (10 min at $1000 \times g$ ) to pellet the nuclear fraction $(\mathrm{P} 1)$ and the supernatant was again centrifuged for $40 \mathrm{~min}$ at $48,000 \times g$ at $4^{\circ} \mathrm{C}$. The pellet (P2) containing the synaptosomal membranes was solubilized in a solution of $1 \%$ Triton X-100, $20 \mathrm{~mm}$ 3-(N-morpholino)propanesulfonic acid (MOPS), pH 7.0, $150 \mathrm{~mm} \mathrm{KCl}$, and a protease inhibitor mixture. The nonsoluble fraction was removed by centrifugation at $1000 \times g$ for $10 \mathrm{~min}$.

Preparation of GluK1 recombinant proteins. The C-terminal domain of GluK1 $1_{\mathrm{b}}$ was subcloned into the pGEX-6P-1 vector (GE Healthcare) and pET-30a-c $(+)$ vector (Invitrogen), and purified from a proteasedeficient BL21 Escherichia coli strain. Two different GST-GluK1 (residues $714-836$ and 743-836) constructs and one His-S-tagged construct (residues 743-836) were also used. The His-S-tagged protein was used as a control in these experiments, a construct containing 18 random amino acids (EFIFTPQSLFSEFVSDDK) with no homology to the C-terminal part of GluK1. All the recombinant proteins were expressed in the BL21 strain of E. coli. The plasmid coding the tagged full-length human mycGluK $_{2 \mathrm{~b}}$ was obtained from Dr. Christophe Mulle (Interdisciplinary Institute for Neuroscience, Bordeaux, France).

GST-bead pull-down assay. Bacterial lysates containing $\geq 5 \mathrm{mg}$ of GST$\mathrm{GluK1}_{\mathrm{b}}$ (residues 714-836 and 743-836) or the GST protein alone (a negative control) was incubated with glutathione-Sepharose beads (GE Healthcare) and allowed to bind for $\geq 120 \mathrm{~min}$ at $4^{\circ} \mathrm{C}$ with gentle rotation. The beads were washed and incubated for $\geq 4 \mathrm{~h}$ at $4^{\circ} \mathrm{C}$ with gentle rotation in the presence of $1 \mathrm{mg} / \mathrm{ml}$ precleared mouse brain homogenate in 20 mм MOPS-KOH, pH 7.3, $150 \mathrm{~mm} \mathrm{KCl,} 2$ mм NaCl, 5 mм MgCl, $1 \%$ Triton X-100, and 5\% glycerol, in the presence of protease inhibitors. A mouse brain homogenate was precleared (overnight at $4^{\circ} \mathrm{C}$ ) by incubation with uncoated glutathione-Sepharose beads and with glutathioneSepharose beads coated with GST.

Tandem affinity purification and S-tag pull-down assay. A bacterial lysate containing the $\mathrm{GluK}_{\mathrm{b}}$ construct or a random 18 aa construct (negative control) was incubated with $\mathrm{Ni}^{2+}$ beads in lysis buffer in the presence of $25 \mathrm{~mm}$ imidazol and $8 \mathrm{~m}$ urea. After extensive washing in high salt buffer $0.5 \mathrm{M} \mathrm{NaCl}, 20 \%$ glycerol, $2 \%$ Triton, and PBS, pH 8, with 50 $\mathrm{mm}$ imidazol and $2 \mathrm{~m}$ urea, the proteins were eluted in $0.25 \mathrm{M}$ EDTA, 20 mм MOPS, pH 7.0, $150 \mathrm{~mm} \mathrm{KCl,} \mathrm{and} \mathrm{1 \%} \mathrm{Triton} \mathrm{X-100} \mathrm{in} 2 \mathrm{~m}$ urea. The proteins were dialyzed in $20 \mathrm{~mm}$ MOPS-KOH, pH 7.3, $150 \mathrm{~mm} \mathrm{KCl}$, and $1 \%$ Triton X-100, and in the same buffer $\sim 500 \mu \mathrm{g}$ of recombinant GluK $1_{b}$ protein or control protein was incubated with S-protein agarose (GE Healthcare) for $1-2 \mathrm{~h}$ to allow binding to the beads. The beads were washed and incubated for $\geq 4 \mathrm{~h}$ at $4^{\circ} \mathrm{C}$ with gentle rotation with $1 \mathrm{mg} / \mathrm{ml}$ total protein from a mouse brain homogenate in $20 \mathrm{~mm}$ MOPS-KOH, pH 7.3, $150 \mathrm{~mm} \mathrm{KCl}, 2 \mathrm{~mm} \mathrm{NaCl}, 5 \mathrm{~mm} \mathrm{MgCl}, 1 \%$ Triton X-100, and 5\% glycerol in the presence of protease inhibitors.

MS and protein identification. After pull down, the protein samples were reduced, alkylated, digested with Trypsin Gold (Promega), and stored at $-20^{\circ} \mathrm{C}$. Tryptic peptides were loaded into an RP- 18 precolumn (LC Packings) using water containing $0.1 \%$ trifluoroacetic acid as the mobile phase, transferred to a nano-HPLC RP- 18 column of $75 \mu \mathrm{m}$ inner diameter (LC Packings), and separated on an acetonitrile gradient ( 0 $50 \%$ acetonitrile over $30 \mathrm{~min}$ ) in the presence of $0.05 \%$ formic acid at a flow rate of $200 \mathrm{nl} / \mathrm{min}$. Liquid chromatography was directly coupled to the ion source of a Q-Tof (Micromass) or LTQ Fourier transform ion cyclotron resonance (Thermo Scientific) electrospray mass spectrometer working in the regime of a data-dependent MS to MS/MS switch. A blank run that ensured a lack of cross-contamination from previous samples preceded each analysis. The MS/MS spectra were submitted to Mascot (Matrix Science; Perkins et al., 1999) and searched against NCBInr, the National Center for Biotechnology Information non-redundant mouse protein database.

Immunoblotting. The proteins obtained in pull-down assays were eluted from the beads with SDS-sample buffer and separated by SDSPAGE on ready gradient $4-20 \%$ polyacrylamide Tris- $\mathrm{HCl}$ gel (Bio-Rad) under reducing conditions in Tris/glycine/SDS running buffer. Proteins separated by SDS-PAGE were transferred to nitrocellulose membranes that were then blocked with $5 \%$ nonfat milk in Tris-buffered salineTween 20 and incubated overnight at $4{ }^{\circ} \mathrm{C}$ with the appropriate primary antibody. Immunoreactive bands were detected with horseradish peroxidase (HRP)-conjugated secondary antibodies, and the band density was quantified on a Bioimager apparatus with ImageJ software.

Antibodies. The following commercially available antibodies were used at the dilutions indicated: rabbit polyclonal anti-G $\alpha$ o (LS-C41953, LifeSpan; Western blot, 1:1000; immunostaining 1:500), chicken polyclonal anti-myc-tag (ab172, Abcam; immunostaining, 1:500), mouse monoclonal anti-myc-tag (sc-40, Santa Cruz Biotechnology; Western blot, 1:500), rabbit polyclonal anti-14-3-3 (PA1-4647, Pierce; Western blot, 1:1000), mouse monoclonal anti- $\beta$-catenin (MAB2081, Millipore; Western blot, 1:1000), rabbit polyclonal anti-4.1G (A301-424A, Bethyl; Western blot, 1:200), goat polyclonal anti-GRIK1 (MBS420225, MyBioSource; Western blot, 1:200), mouse monoclonal anti-GRIP (G90520, BD Biosciences; Western blot, 1:600), goat polyclonal anti-PICK1 (SC9541, Santa Cruz Biotechnology; Western blot, 1:500), mouse monoclonal anti-RAB 3a (107 111, Synaptic Systems; Western blot, 1:1000). The secondary antibodies used were as follows: Alexa 555-conjugated chicken anti-rabbit and Alexa 488-conjugated goat anti-chicken (Invitrogen; 1:500). In immunoblots, HRP-conjugated goat anti-rabbit or antimouse, and rabbit anti-goat secondary antibodies (Pierce) were used.

Immunoprecipitation. Immunoprecipitation was performed as described previously (Selak et al., 2009). Briefly, lysates from cell lines cotransfected with myc-GluK1 $1_{\mathrm{b}}$ and flag-G $\alpha$ o were precleared by incubating with protein A (GE Healthcare) or protein-G Sepharose (SigmaAldrich) in $20 \mathrm{~mm}$ MOPS, pH 7.0, $150 \mathrm{~mm} \mathrm{KCl}$, and 1\% Triton X-100 for $1 \mathrm{~h}$ at $4^{\circ} \mathrm{C}$, to eliminate nonspecific binding. Immunoprecipitation was performed by incubating lysates with mouse anti-myc or anti-flag antibodies, or control normal mouse immunoglobulins, covalently coupled to protein $\mathrm{A} / \mathrm{G}$ with dimethyl pimelimidate dihydrochloride and incubated for $4 \mathrm{~h}$ or overnight at $4^{\circ} \mathrm{C}$ in the presence of BSA. The beads were washed and suspended in sample buffer before electrophoresis.

Immunocytochemistry. SHSY5Y cells were seeded on poly-D-lysinecoated coverslips and transfected using Lipofectamine 2000. Twentyfour hours after transfection, the cells were fixed for $2 \mathrm{~min}$ in $4 \%$ paraformaldehyde/ $10 \%$ sucrose and then washed extensively with PBS. The cells were incubated with a chicken anti-myc antibody $(2 \mathrm{~h}$, room temperature) and then permeabilized for $10 \mathrm{~min}$ in PBS containing $0.2 \%$ Triton X-100. Permeabilized cells were incubated with the G $\alpha$ o rabbit primary antibody ( $2 \mathrm{~h}$, room temperature) and then with Alexa 555conjugated anti-chicken and Alexa 488-conjugated anti-rabbit secondary antibody. The coverslips were mounted with Vectashield (Vector Laboratories) and examined under a Leica DMLFSA spectral confocal 
microscope using oil-immersion PL Apo $40 \times / 1.25$ numerical aperture or $63 \times / 1.32$ numerical aperture objectives.

Monitoring bioluminescence resonance energy transfer in living cells. HEK cells in 96-well microplates were transfected using Lipofectamine 2000 (Invitrogen) with $\mathrm{G} \gamma_{2}$-yellow fluorescent protein (YFP), G $\alpha$ o-Rluc (Renilla luciferace) and $\mathrm{G} \beta$, and either mGluR2, Vasopressin (V2), $\mathrm{GluK}_{2 \mathrm{~b}}$, GluK1 $\Delta \mathrm{C}$, or GluK1 $1_{2 \mathrm{~b}}+\mathrm{GluK} 5$. After $24 \mathrm{~h}$, the cells were washed with PBS and coelenterazine $\mathrm{H}$ substrate (Invitrogen) was added at a final concentration of $5 \mu \mathrm{M}$ in the total volume of $50 \mu \mathrm{l} / \mathrm{well}$, in the presence or absence of ligands and/or inhibitors. Readings were taken immediately with a lumino/fluorometer (Fusion, Packard Instrument) with sequential integration of luminescence signals detected using two filters: $485 \mathrm{~nm}$ for Rluc8 and $530 \mathrm{~nm}$ for YFP. Bioluminescence resonance energy transfer (BRET) signals were expressed in milliBRET units of the BRET ratio as described previously (Ayoub et al., 2002).

Bimolecular fluorescence complementation. Myc-GluK $1_{2 \mathrm{~b}}$ VCT, MycGluK1 $1_{2} \Delta C^{\mathrm{VCT}}$, Myc-GluK5 ${ }^{\mathrm{VNT}}$, and Myc-GluK4 ${ }^{\mathrm{VNT}}$ were generated by fusing the C-terminal domain (V155) of Venus (VCT) to the C terminus of myc-GluK1 $1_{2 b}$, myc-GluK1 $1 \mathrm{C}$, or myc-GluK5, respectively. MycGluK4, Myc-GluK5, and myc-GluK5 $\Delta \mathrm{C}$ were also fused to the $\mathrm{N}$-terminal domain of Venus (V154m9; VNT) as described previously (Selak et al., 2009). For the G $\alpha$ o subunit, both parts of the Venus protein were fused to the $\mathrm{G} \alpha$ o protein in the loop after residue $\mathrm{Val}^{93}$, as described previously (Ayoub et al., 2009), generating G $\alpha_{\mathrm{O}}{ }^{\mathrm{VNT}}$ or G $\alpha \mathrm{O}^{\mathrm{VCT}}$.

A combination of plasmids were cotransfected into HEK cells using Lipofectamine 2000 (Invitrogen) according to the manufacturer's instructions. After $24 \mathrm{~h}$, the cells were used for immunostaining or FACS analysis. To check for protein expression, dual immunostaining was performed with antibodies against myc and G $\alpha$ o. Colocalization of Venus, myc, and G $\alpha$ o was visualized on a Leica DMLFSA spectral confocal microscope. For FACS analysis, detached live transfected cells were washed with PBS and measured on a FACSARIA III cell sorter (BD Biosciences). Background fluorescence was determined in HEK cells transfected with the empty vectors and with a GFP vector as a positive control. BD FACSDiva software was used to analyze the data.

Electrophysiological recordings in dissociated DRG neurons. Dissociated DRG neurons from P0 C57 mice (male and female pups) were prepared as described previously (Rozas et al., 2003; Marques et al., 2013). One day after dissociation, afterhyperpolarization current $\left(I_{\mathrm{AHP}}\right)$ was induced with $80 \mathrm{~ms}$ depolarizing pulses to $-10 \mathrm{mV}$ from $-50 \mathrm{mV}$ under perforated patch whole-cell configuration using a List EPC-7 amplifier. Perforated patches were achieved using the antibiotic amphotericin $\mathrm{B}$, with an internal solution containing $135 \mathrm{~mm} \mathrm{KMeSO}$, 10 mм HEPES, $4 \mathrm{~mm}$ $\mathrm{MgCl}_{2}$, and $500 \mathrm{mg} / \mathrm{ml}$ amphotericin $\mathrm{B}, \mathrm{pH}$ 7.4. The pipette tip was filled with an amphotericin B-free internal solution, and an antibioticcontaining internal solution was used to fill the rest of the pipette. The external solution contained the following: $160 \mathrm{~mm} \mathrm{NaCl}, 2.5 \mathrm{~mm} \mathrm{KCl}, 1.8$ $\mathrm{mm} \mathrm{CaCl}_{2}, 1 \mathrm{~mm} \mathrm{MgCl}_{2}, 10 \mathrm{~mm}$ HEPES, and $15 \mathrm{~mm}$ glucose, $\mathrm{pH}$ 7.4. The borosilicate glass micropipettes used had resistances of 2-5 M $\Omega$. For perforated whole-cell configuration, recordings were initiated when the series resistance was $<20 \mathrm{M} \Omega$, which was compensated by $60-80 \%$. All experiments were performed at room temperature $\left(22-25^{\circ} \mathrm{C}\right)$. The currents were filtered at $1 \mathrm{kHz}$ (two-pole Butterworth filter, $-12 \mathrm{~dB} /$ octave) and digitized at $20 \mathrm{kHz}$ to store on a personal computer for analysis using pClamp software (Axon Instruments).

\section{Results}

Purification and proteomic analysis of the GluK1 interactome The capacity of metabotropic signaling by KARs can be reproduced in a recombinant system by simply expressing $\mathrm{GluK}_{2 \mathrm{~b}}$ subunits (Rivera et al., 2007) and in neurons this noncanonical signaling depends on the presence of GluK1 (Rozas et al., 2003). Since GluK1 subunits are most likely to interact with G-proteins, we focused our attention on this particular subunit. GluK1 may have four different C-terminal domains that are generated by alternative splicing. The carboxy terminus of the "a" variant is 49 aa shorter than that of the " $b$ " variant, which is the most abundant isoform in the brain (Sommer et al., 1992). The "c" variant contains an extra in-frame exon
Table 1. Identified proteins interacting with the $\mathrm{C}$ terminus of the KAR subunit Gluk1

\begin{tabular}{|c|c|c|c|c|c|}
\hline Name & NCBI number ${ }^{a}$ & Percentage coverage & Peptides & GluK1a & $\overline{\text { Gluk1b }}$ \\
\hline $\mathrm{G} \alpha 0^{b}$ & gi|6754012 & 27 & 9 & + & + \\
\hline HSC70 & gi|309319 & 19 & 16 & + & + \\
\hline $\mathrm{HSP} 70.2^{b}$ & gi|31560686 & 16 & 9 & + & + \\
\hline GAPDH & gi|55153885 & 26 & 20 & + & + \\
\hline $14-3-3 \eta^{b}$ & gi|6756037 & 24 & 7 & + & + \\
\hline $14-3-3 \gamma^{b}$ & gi 9507245 & 36 & 10 & + & + \\
\hline $14-3-3 \theta^{b}$ & gi|6756039 & 35 & 8 & + & + \\
\hline $14-3-3 \zeta^{b}$ & gi|1841387 & 45 & 15 & + & + \\
\hline Triosephosphate isomerase & gi|148667347 & 41 & 7 & + & + \\
\hline Glutamate transporter & gi|2459554 & 20 & 7 & + & + \\
\hline $\mathrm{GAP} 43^{b}$ & gi|6679935 & 43 & 8 & + & + \\
\hline CEND1 & gi|10946620 & 41 & 6 & + & + \\
\hline Basp $1^{b}$ & gi|45598372 & 61 & 12 & + & + \\
\hline ATPase5a & gi|203055 & 36 & 18 & + & + \\
\hline $\mathrm{RAB} \mathrm{A}^{b}$ & gi| 6679593 & 21 & 3 & + & + \\
\hline PurA & gi|6679573 & 54 & 17 & + & + \\
\hline PurB & gi 6755252 & 55 & 12 & - & + \\
\hline MAP1 & gi|122065442 & 23 & 13 & + & + \\
\hline CaMKII $\alpha^{b}$ & gi 6978593 & 24 & 11 & + & + \\
\hline Synapsin $\|^{b}$ & gi 8567410 & 43 & 7 & + & + \\
\hline $4.1 \mathrm{G}^{b}$ & gi|28172874 & 17 & 11 & - & + \\
\hline MAP6, neuronal-STOP & gi|113204613 & 16 & 10 & + & + \\
\hline
\end{tabular}

${ }^{a}$ The National Center for Biotechnology Information protein accession numbers.

${ }^{b}$ Proteins found relevant to KAR biology.

that makes it 29 aa longer than the "b" isoform, while variant " $d$ " has been isolated from human tissue and it has a completely unrelated 15 aa stretch that starts at Q824 (for review, see Lerma, 2003). These C-terminal domains all lie in the intracellular part of the protein, making them suitable to participate in protein-interaction.

To isolate proteins that interact with the C-terminal domain of the abundant GluK1 $1_{b}$ subunits, we first subjected a total brain homogenate to a pull-down assay using the last 122 aa of GluK $1_{b}$ or the shorter C-term of GluK1 $1_{\mathrm{a}}$ fused to GST and immobilized on beads as bait (GST-GluK1 $\left.1_{\mathrm{b} 714-836}\right)$. The protein mixture was digested with trypsin before separating the individual components by liquid chromatography and further analyzing the peptide mix by MS (LC-MS/MS; Link et al., 1999). The protein fragments recovered were identified with the Mascot engine (Perkins et al., 1999) and each of the proteins identified was manually verified to minimize the identification of false positives, removing redundant proteins (i.e., those coming from one gene but reported as separate proteins in the database and, therefore, identified more than once). Proteins were considered to interact specifically with GluK1 if they were eluted from the test beads but were not present in the material isolated with the control beads. We repeated this procedure independently six times and obtained a list of 100 proteins that were putative interactors with GluK $1_{\mathrm{b}}$. Only proteins identified through $\geq 2$ specific peptides were chosen for further analysis and candidates present in $<2$ purifications or with sequence coverage $<10 \%$ were not considered. Accordingly, 22 proteins were considered to interact specifically with the GluK $1_{\mathrm{b}}$ isoform (Table 1 ). These proteins included those associated with signal transduction ( $\mathrm{G} \alpha \mathrm{O}$ subunits, CaMKII), cell metabolism, presynapses (Rab3a, synapsin II), and the cytoskeleton and structural elements ( $\beta$-catenin, $4.1 \mathrm{G})$, and those proteins involved in vesicular trafficking (14-3-3). Additional proteins involved in the control of cellular energy production, as well as a group of proteins known to be important in transcription and translation, were also identified. However, some of the proteins identified, despite passing the threshold criteria (e.g., GAPDH or 
Pur proteins) have little functional relevance in terms of receptor biology. As a result of these exclusion criteria, only 12 proteins were considered as promising partners and were subjected to further analysis (Table 1). Surprisingly, some known GluK1 C-terminal interactors were not identified in the MS analysis, such as GRIP and PICK1 (Hirbec et al., 2003), although they were later confirmed to be present in the sample.

The interaction of the proteins identified with KAR subunits was confirmed in Western blots, probing the products pulled down with specific antibodies. To this end, pull-down assays were performed using a S-tag GluK1 C-terminal domain $\left(\mathrm{S}-\mathrm{GluK} 1_{\mathrm{b} 714-836}\right)$ rather than the GST constructs used to isolate the starting material, and the efficacy of interaction was quantified (Fig. 1). The proteins could be separated into three main groups: those enriched $\sim 30$-fold (4.1G, $\beta$-catenin, and GRIP), those enriched $\leq 10$-fold (e.g., GAP43, CaMKII, and $\mathrm{G} \alpha \mathrm{o}$ ), and those enriched $>100$-fold (143-3 and PICK1). In Western blots, we confirmed the presence of six proteins interacting with $\mathrm{GluK}_{\mathrm{b}}$ in independent purifications (Fig. 1). As a control we included GRIP and PICK1, which are known interactors of GluK1 (Hirbec et al., 2003), although they were not identified by MS analysis. In addition, an interaction with $\beta$-catenin was confirmed, although the MS evidence for this interaction was weak (protein identified by $\leq 2$ specific peptides and in $\leq 2$ independent MS analyses). Significantly, CaMKII, 4.1G, and 14-3-3 proteins are known to interact with glutamate receptors, and $14-3-3 \zeta$ has been shown to interact with $G l u K 1_{b}$ (Vivithanaporn et al., 2006). By contrast, the other proteins identified were not previously known to interact with glutamate receptors.

\section{Goo interacts with GluK1}

G $\alpha$ o was detected in all the GluK1 $1_{\mathrm{b}}$ and GluK1 $1_{\mathrm{a}}$ MS analyses, although G $\alpha$ o appeared to be more specific for the " $b$ " isoform when analyzed independently in Western blots (Fig. 2A). Since the pulldown data strongly suggested a physical interaction between $\mathrm{GluK} 1_{\mathrm{b}}$ and $\mathrm{G} \alpha \mathrm{O}$ proteins, their colocalization in cells was assessed by confocal microscopy of tagged proteins. In the absence of specific antiGluK1 antibodies, cells were transfected with a myc-GluK1 $1_{b}$ plasmid containing five repeats of the myctag in the extracellular domain. This modification does not influence ionotropic receptor function (data not shown) and it is unlikely to cause interference with the C-terminal domain of

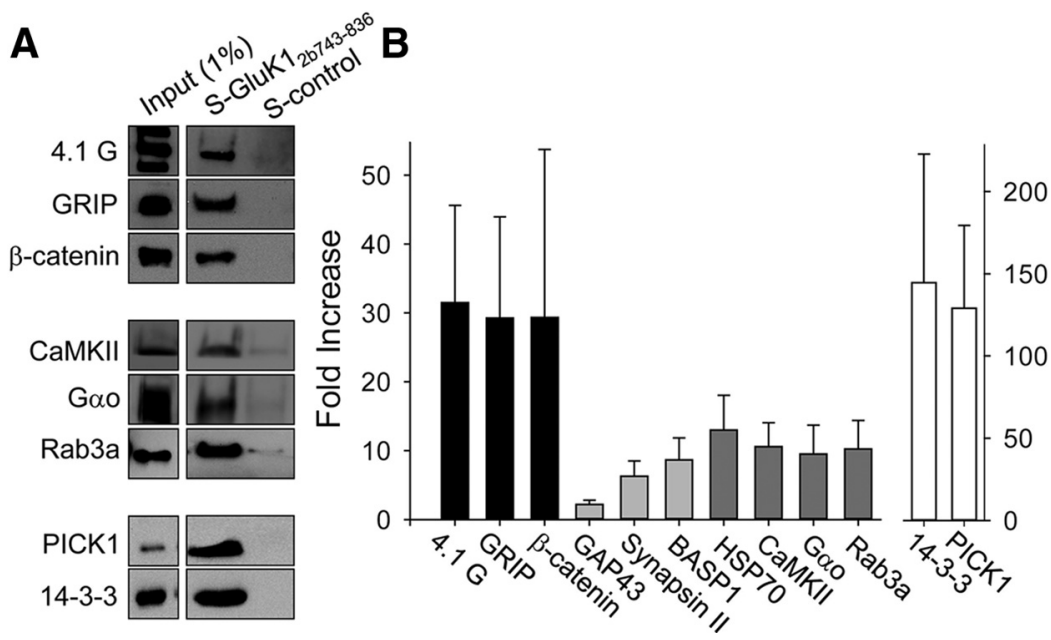

Figure 1. Assessing the GluK1 receptor interactome in pull-down assays. A, Recombinant protein (S-GluK1 $\mathrm{C}_{\mathrm{b}} \mathrm{C}$-terminal or control construct) bound to S-protein agarose was incubated with a mouse brain homogenate to pull-down interacting proteins, which werestudied in immunoblots with the antibodies indicated. B, Average densitometry quantification from three independent experiments and, depending on the enrichment, the proteins may be divided into three groups. Note that $G \alpha 0$ appears as a protein that clearly interacts with the GluK1 subunit.
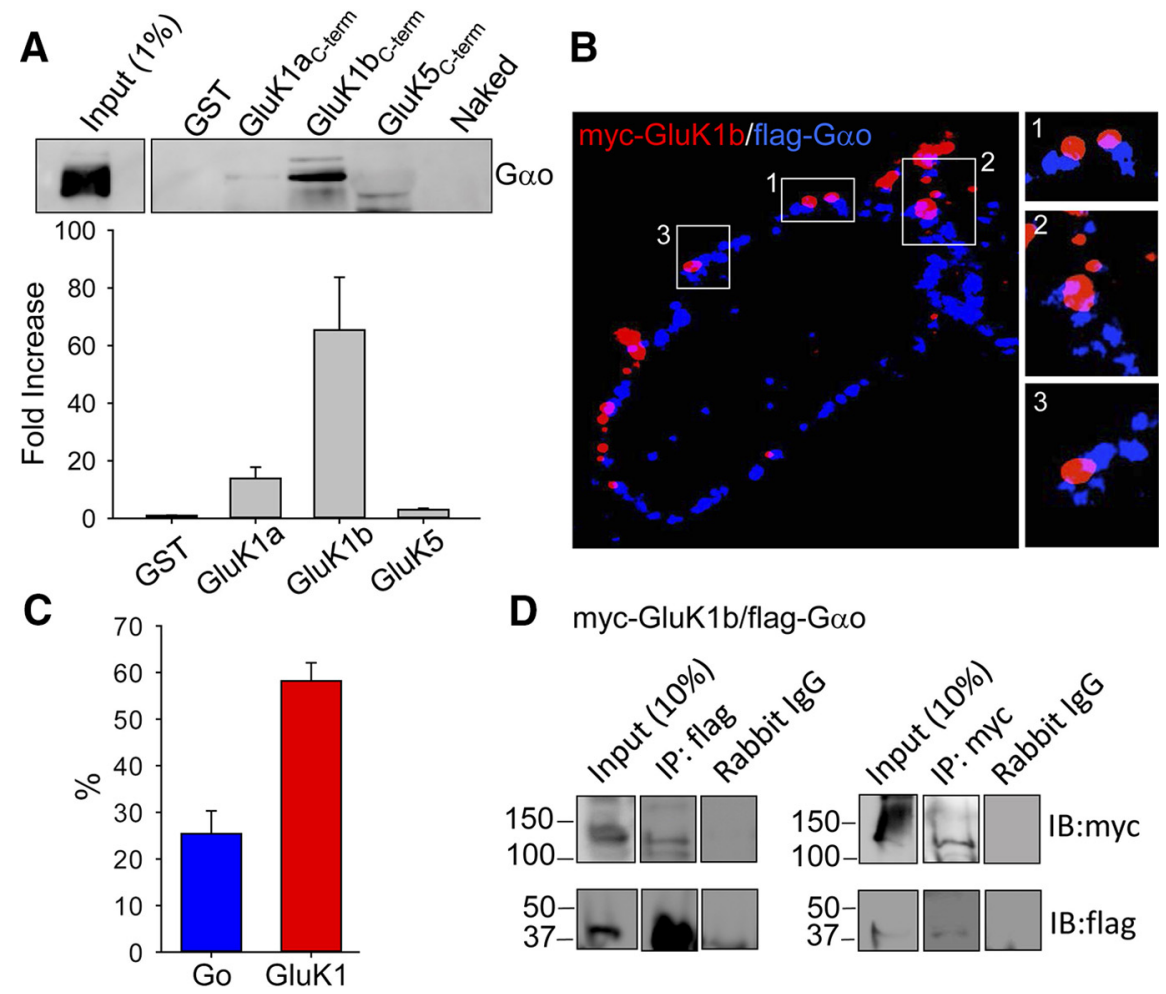

D myc-GluK1b/flag-G $\alpha 0$

Figure 2. Colocalization of myc-GluK1 $1_{b}$ and G $\alpha 0$ in SH-SY5Y cells. A, GST-based pull-down revealed that G $\alpha 0$ specifically interacts with the C-terminal domain of GluK1 $1_{b}$. Measurements are the mean \pm SEM from six (GST, GluK1 $1_{a}$ and GluK5) and eight $\left(G l u K 5_{b}\right)$ different pull-down experiments and are referenced against GST band density. $\boldsymbol{B}$, Colocalization of membrane $G$ luK $1_{b}$ and $\mathrm{G} \alpha 0$ in SH-SY5Y cells transfected with both proteins. Confocal images show the overlapping immunofluorescence of flag- $\mathrm{G} \alpha 0$ (blue) and myc-GluK1 $1_{b}$ (red) in cotransfected cells. C, Quantification of these images show that $25.9 \pm 4.9 \%$ of the blue dots (flag-G $\alpha$ 0) colocalize or lie in close proximity to the red dots (myc-GluK1 $1_{b}$, extracellularly labeled), and $58.2 \pm 3.25 \%$ of red dots colocalize with blue dots. The data are the mean \pm SEM of measurements from 15 cells. D, The G $\alpha 0$ subunit coimmunoprecipitates GluK1 ${ }_{b}$. Extracts from SH-SY5Y cells cotransfected with myc-GluK ${ }_{b}$ and flag-G $\alpha 0$ were immunoprecipitated (IP) with a rabbit anti-flag, anti-myc, or appropriate lg $G$ antibody and probed in Western blots (IB) with anti-myc or anti-flag antibodies as indicated.

GluK1 (Rivera et al., 2007). In this case, an interaction between GluK1 and G $\alpha$ o can be presumed either through the overlap of the fluorescent signal or when one fluorescent signal is in close spatial proximity to the other. 


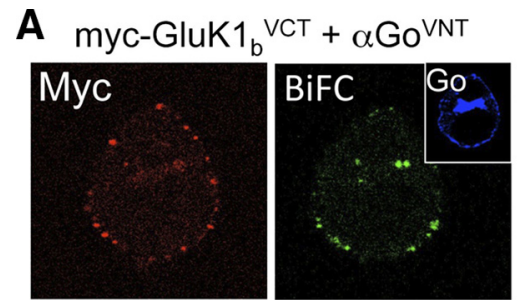

B myc-GluK $1 \Delta \mathrm{Cl}^{\mathrm{VCT}}+\alpha \mathrm{GovNT}^{\mathrm{VNT}}$
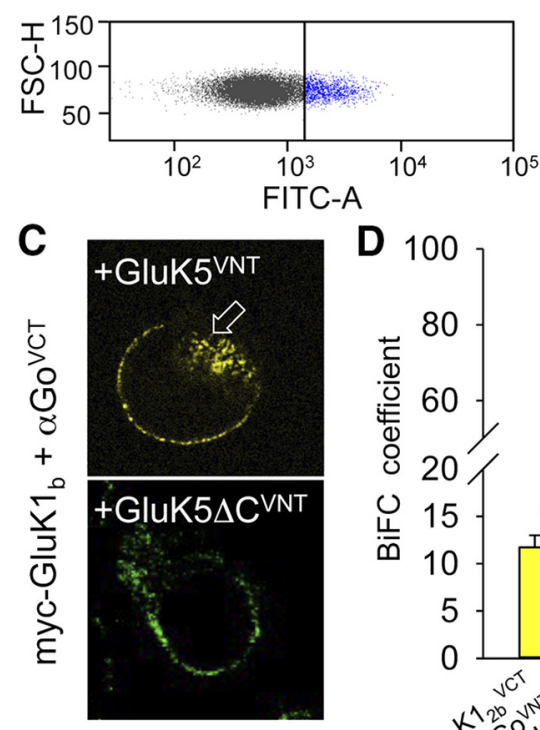
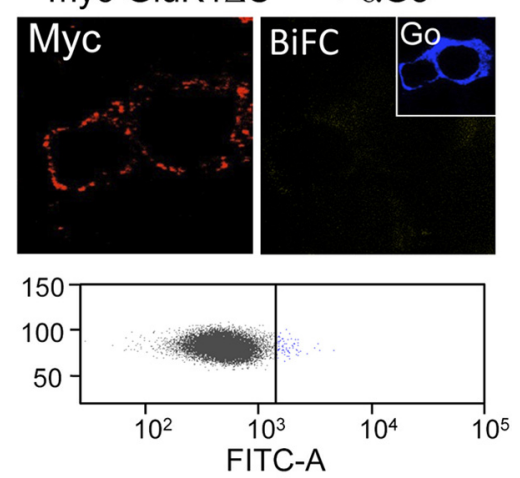

D 100
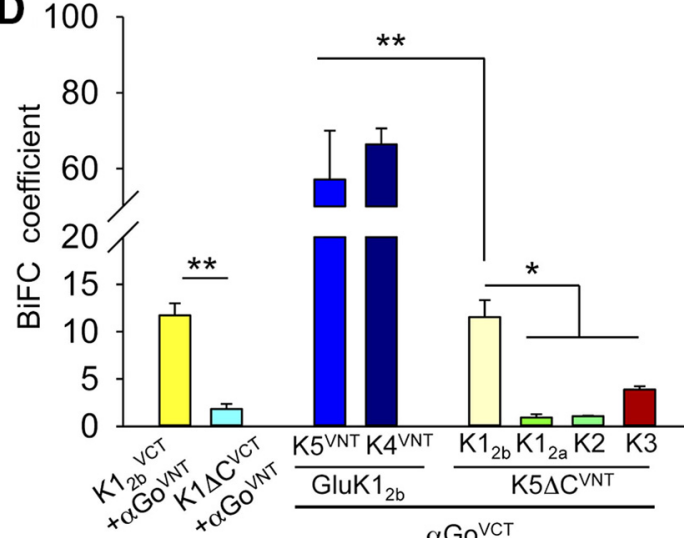

$\alpha \mathrm{Go}^{\mathrm{VCT}}$

Figure 3. G $\alpha 0$ interacts with GluK1 subunits in a cell system. $A$, HEK293 cells transfected with the myc-GluK1 $1_{b}$ and G $\alpha 0$ fusion proteins to which the C-terminal (VCT) and N-terminal (VNT) domains of the Venus YFP variant had been respectively added. Single confocal images showing the immunolabeling of extracellular myc (Myc, red) and intracellular $\mathrm{G}_{\alpha 0}$ ( $\mathrm{Go}$, blue), as well as the reconstitution of Venus fluorescence (yellow). $\boldsymbol{B}$, Removal of the C-terminal domain of GluK1 (GluK1 $\Delta C^{\mathrm{VCT}}$ ) selectively prevented the fluorescence complementation in cells showing normal levels of the expressed proteins. Dot plots of the FACS analysis are shown below $\boldsymbol{A}$ and $\boldsymbol{B}$. These represent the fluorescence intensity (exponential arbitrary units, FITC-A) against cell complexity (FSC-H). Gray and blue dots represent the nonfluorescent and fluorescent cell populations, respectively (100,000 cells sorted in each case). C, BiFC in cells transfected with $G \alpha 0^{\mathrm{VCT}}$, myc-GluK1 ${ }_{\mathrm{b}}$, and myc-GluK5 ${ }^{\mathrm{VNT}}$. Note how fluorescence accumulates intracellularly when GluK1 and GluK5 ${ }^{\mathrm{VNT}}$ form heterodimers (top, arrow), a phenomenon that disappears upon removal of the C-terminal domain of GluK5 (bottom). D, Quantification of BiFC by FACS under different experimental conditions. The data are the mean \pm SEM of four independent experiments, each performed in triplicate. ${ }^{*} p<0.05,{ }^{* *} p<0.01$ (1-way repeated-measures ANOVA, Tukey's test).

We first assessed whether transfected GluK $1_{\mathrm{b}}$ and endogenous G $\alpha$ o colocalized in SH-SY5Y cells since we have evidence that transfection of GluK1 $1_{\mathrm{b}}$ reconstitutes noncanonical KAR signaling in these cells (Rivera et al., 2007). Cells were fixed and immunostained with a primary/secondary antibody pair specific to the G-protein tested, and an anti-myc antibody that only recognized GluK1 in the membrane (Fig. 2B, where whole cells and the magnification of selected regions are illustrated). All the cells expressed $\mathrm{G} \alpha \mathrm{o}$, and $\mathrm{G} \alpha \mathrm{o}$-rich complexes were scattered throughout the plasma membrane (punctate fluorescence). However, colocalization of GluK1 and G $\alpha$ o was particularly evident at some areas of the cell, and while $\sim 50 \%$ of the GluK1 aggregates colocalized or were in close proximity to $\mathrm{G} \alpha \mathrm{o}$, only $\sim 25 \%$ of the $\mathrm{G} \alpha \mathrm{o}$ fluorescence appeared to colocalize with the receptor (Fig. 2C). Nevertheless, when endogenous $\mathrm{G} \alpha \mathrm{o}$ was immunoprecipitated from these cells, we were unable to detect an association with myc-GluK1, probably because the ratio of GluK1 to G $\alpha$ o was too high or, alternatively, the G $\alpha$ o antibody performed poorly in these assays. Therefore, SH-SY5Y cells were cotransfected with plasmids for myc-GluK $1_{2 \mathrm{~b}}$ and also with a flag-tagged variant of $\mathrm{G} \alpha \mathrm{o}$, further analyzing the cells with antibodies against myc and the flag epitope (Fig. 2D). From the lysates of these cells, myc-tagged GluK $1_{2 b}$ could be coimmunoprecipitated with flagtagged $\mathrm{G} \alpha$ o protein, and vice versa, indicating that this interaction is probably direct and does not require any additional proteins to mediate or stabilize the interaction.

These biochemical approaches indicate there is a true interaction between GluK1 and $\mathrm{G} \alpha \mathrm{o}$, which we therefore attempted to confirm in vivo by bimolecular fluorescence complementation (BiFC; Kerppola, 2006). $\mathrm{BiFC}$ involves the use of two nonfluorescent amino-terminal and carboxy-terminal fragments of the YFP that, when in close apposition, interact to irreversibly reconstitute the fluorescent protein. Thus, $\mathrm{BiFC}$, besides showing the subcellular distribution of these complexes, should indicate whether the protein interaction between $\mathrm{GluK}_{\mathrm{b}}$ and the $\mathrm{G} \alpha \mathrm{o}$ protein is direct and independent of additional proteins. For these studies, we used an optimized version of the YFP variant, Venus (Saka et al., 2007), generating constructs of the N-terminal domain (V154m9) of Venus fused to $\mathrm{GluK1}_{\mathrm{b}}\left(\mathrm{GluK1}{ }^{\mathrm{VCT}}\right)$ and of its C-terminal domain (V155) fused to $\mathrm{G} \alpha \mathrm{O}\left(\mathrm{Go}^{\mathrm{VNT}}\right)$. In addition, to demonstrate the presence of GluK1 and G $\alpha \mathrm{o}$ in the same cell, dual immunocytochemistry was performed using antibodies against myc and G $\alpha 0$ (Fig. 3). Cotransfection of $\mathrm{GluK}_{2 \mathrm{~b}}^{\mathrm{VNT}}$ and Go ${ }^{\mathrm{VCT}}$ led to the reconstitution of Venus in these cells (Fig. 3A), while removal of C-terminal domain of $\mathrm{GluK1}_{2 \mathrm{~b}}\left(\right.$ myc-GluK1 $\left.\Delta \mathrm{C}^{\mathrm{VCT}}\right)$ selectively prevented fluorescence complementation in cells in which these GluK1 and G $\alpha$ o constructs were expressed (Fig. 3B). As a further control, the viability of mycGluK1 $1 \Delta \mathrm{C}^{\mathrm{VCT}}$ was assessed by its cotransfection with GluK5 fused to the N-terminal domain of Venus $\left(\mathrm{GluK} 5_{2 \mathrm{~b} T}^{\mathrm{VNT}}\right)$. Heteromerization of these subunits to form a functional KAR produced strong fluorescence complementation in a large number of cells (data not shown), indicating that reduced viability of the GluK1deletion mutant could not explain the failure to detect complementation with this mutant construct. BIFC was further assessed by FACS, which enabled us to quickly analyze large numbers of cells, typically 100,000 cells in each trial. Using this method, we studied the interaction of heteromeric GluK1 $1_{2 \mathrm{~b}} / \mathrm{GluK} 5$ receptors with the $\mathrm{G} \alpha$ o protein, with the unexpected result that BiFC was totally abolished when the GluK1 $1_{2 \mathrm{~b}}^{\mathrm{VNT}}$ and GluK5 plasmids were transfected with $\mathrm{Go}^{\mathrm{VNT}}$. We reasoned that the introduction of a second subunit in the heteromeric receptor might preclude the access of the VCT hemiprotein to the VNT hemiprotein, failing to reconstitute the fluorescent marker. However, when we fused VNT to the end of the GluK5 or GluK4 C-terminal domain rather than to $\mathrm{GluK}_{\mathrm{b}}$, generating GluK5${ }^{\mathrm{VNT}}$ and $\mathrm{GluK} 4^{\mathrm{VNT}}$, the expression of these subunits together with $\mathrm{GluK}_{2 \mathrm{~b}}$ surprisingly generated a fourfold larger BiFC signal, probably due to the presence of intracellular fluorescent aggregates (Fig. 3C). Removal of 
the C-terminal domain of GluK5 reversed this effect and BiFC reverted to a similar intensity as when GluK $1_{2 b}$ was the carrier of the VCT fragment. Using this same approach, we studied BiFC of heteromeric receptors incorporating $\mathrm{GluK}_{2 \mathrm{a}}$ (the shortest C-terminal segment), GluK2, or GluK3, in all cases failing to detect significant BiFC signal (Fig. 3D).

Together, these results strongly support the idea that $\mathrm{G} \alpha$ o proteins interact with the carboxy terminus of GluK1 in a cellular system, strengthening the notion that $\mathrm{GluK} 1_{\mathrm{b}}$ and $\mathrm{G} \alpha \mathrm{o}$ interact in vivo.

\section{Functional coupling between GluK $1_{b}$ and Go proteins}

Functional coupling of the KARs to heterotrimeric $\mathrm{G} \alpha$ o proteins was validated in HEK cells by BRET. A change of energy transfer on exposure to an agonist is taken as an indicator of the association/dissociation of proteins, or a transition from their inactive to active state. Indeed, an agonist-induced decrease in energy transfer has been linked to the reversible dissociation of G-protein subunits (Figure 4A; Janetopoulos et al., 2001; Yi et al., 2003). Therefore, we used BRET to monitor the coupling between GluK1 $1_{\mathrm{b}}$ and G $\alpha$ o protein in living cells, fusing the $\mathrm{G} \alpha$ o subunit to the Renilla reniformis luciferase enzyme

(Rluc) while the $\gamma$ subunits were fused to YFP. Both constructs were transiently transfected into HEK cells along with GluK $1_{2 b}$ or GluK $1_{2 b} /$ GluK5 KAR subunits, and in these experiments we used mGluR2 and vasopressin 2 receptors (V2) as positive and negative controls of $\mathrm{G} \alpha \mathrm{o}$ protein coupling, respectively. As expected, glutamate promoted a decrease in the basal BRET signal between the $\alpha$ and $\beta \gamma$ subunits of G $\alpha$ o in mGluR2-cotransfected cells, indicating the rapid dissociation of the $\alpha$ subunit from the $\beta \gamma$ complex upon receptor activation (Fig. $4 B$ ). By contrast, glutamate was completely ineffective in V2-cotransfected cultures. Similarly, exposure to glutamate induced a large decrease in the BRET signal between $\mathrm{G} \alpha \mathrm{O}$ and $\mathrm{G} \gamma$ subunits in $\mathrm{GluK} 1_{2 \mathrm{~b}}$-cotransfected and GluK $1_{2 b} /$ GluK5-cotransfected cells, and this signal was also significantly reduced when the carboxy terminal domain of GluK $1_{2 b}$ subunit was removed (Fig. $4 B$ ). The reduction in the $G l u K 1_{2 b}$-mediated BRET signal induced by glutamate was dose dependent and we calculated an $\mathrm{EC}_{50}$ value of $50.4 \mu \mathrm{M}$ with a Hill slope close to 0.5 (Fig. 4C). Moreover, the glutamate-induced change in BRET was prevented by an antagonist of the GluK1 receptor, such as UBP310 (Fig. 4D), or the more generic AMPA-KAR inhibitor, DNQX (data not shown).

Together, these data demonstrate that stimulation of GluK $1_{\mathrm{b}^{-}}$ containing receptors activates the $\mathrm{G} \alpha \mathrm{o}$ protein in cells, a direct demonstration of noncanonical signaling of an ionotropic receptor subunit.

Noncanonical signaling is absent in GluK1-deficient animals If $\mathrm{GluK} 1_{\mathrm{b}}$ were the receptor subunit linking glutamate binding to KARs to $\mathrm{G} \alpha \mathrm{o}$ activation and its subsequent signaling, then such signaling should be absent in mice lacking GluK1 subunits. DRGs exclusively express GluK1 and GluK5 subunits, representing a
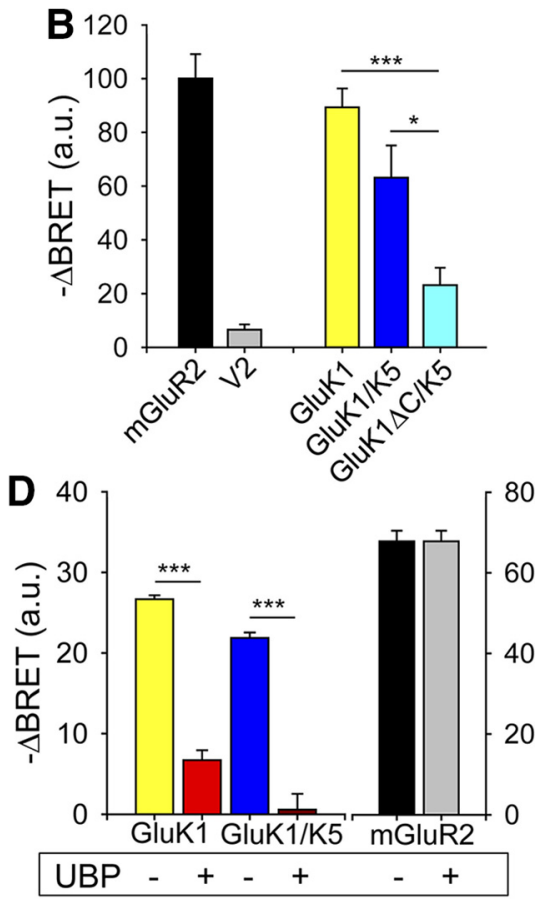

80 60 40 20

Figure 4. GluK1 activates $\mathrm{G} \alpha$ o proteins. $\boldsymbol{A}$, Diagram representing the BRET assay used to study activation of a heterotrimeric in the GluK1-induced loss of the BRET signal. D, The KAR antagonist UBP310 (100 $\mu \mathrm{m})$ inhibits the activation of heterotrimeric $\mathrm{G} \alpha 0 / \beta \gamma$ complex by GluK1 but not by mGluR2 receptors. The data in $\boldsymbol{B}$ and $\boldsymbol{D}$ are the mean $\pm \mathrm{SEM}$ of three independent experiments, each performed in triplicate. ${ }^{*} p<0.05,{ }^{* * *} p<0.001$ (Student's $t$ test).

suitable system to test this hypothesis. Moreover, KARs are known to inhibit the $I_{\mathrm{AHP}}$ through the activation of a pertussissensitive G-protein (Melyan et al., 2002), a current mediated by $\mathrm{Ca}^{2+}$-dependent $\mathrm{K}^{+}$channels responsible for hyperpolarization after action potential firing, offering a suitable readout of noncanonical ionotropic receptor signaling. To test whether the presence of GluK1 is required for G-protein-mediated KAR signaling, we first determined whether an $I_{\mathrm{AHP}}$ could be detected in dissociated DRG neurons (Fig. 5A), thereafter assessing its modulation by kainate. Having identified an $I_{\mathrm{AHP}}$ in these neurons, we found it to be inhibited by $22.7 \pm 1.15 \%$ in $44 \%$ of the cases when they were exposed to low concentrations of kainate (100 nM). This inhibitory effect was totally absent in neurons dissociated from GluK1 ${ }^{-l-}$ mice $(-3.8 \pm 0.9 \%$; Fig. $5 A, B)$, whereas a similar inhibitory effect of kainate was still evident in neurons from GluK5 ${ }^{-1-}$ mice (Fig. 5B). Hence, it appears that $\mathrm{G} \alpha \mathrm{O}$ is not activated in the absence of GluK1 subunits and that GluK5 does not contribute to the coupling of these receptors to $\mathrm{G} \alpha$ o proteins.

\section{Discussion}

We have identified here a number of proteins that interact with the C-terminal domain of the GluK1 subunit of KARs, some of which were already known to interact with KARs and some that were involved in the trafficking of these receptors. For instance, our analysis identified two major proteins interacting with GluK1: $4.1 \mathrm{G}$, which belongs to the 4.1 protein family of cytoskeletal adaptor proteins and may be involved in KAR trafficking, synaptic targeting, and the dynamic regulation of receptor endocytosis as it has been found for the 4.1G variant (Copits and Swanson, 2013); and isoforms of the 14-3-3 protein, a widely expressed family of chaperone proteins that have been implicated 
A
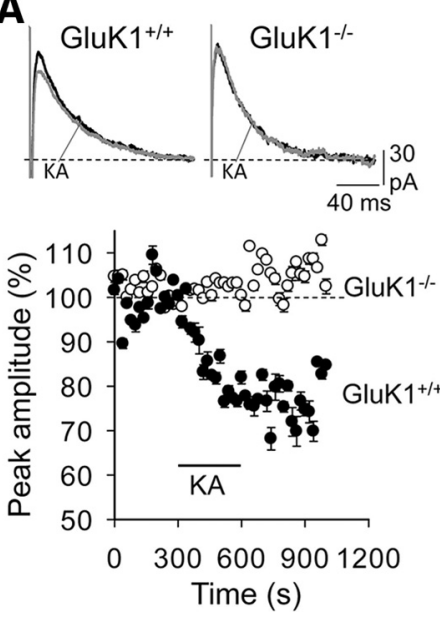

B
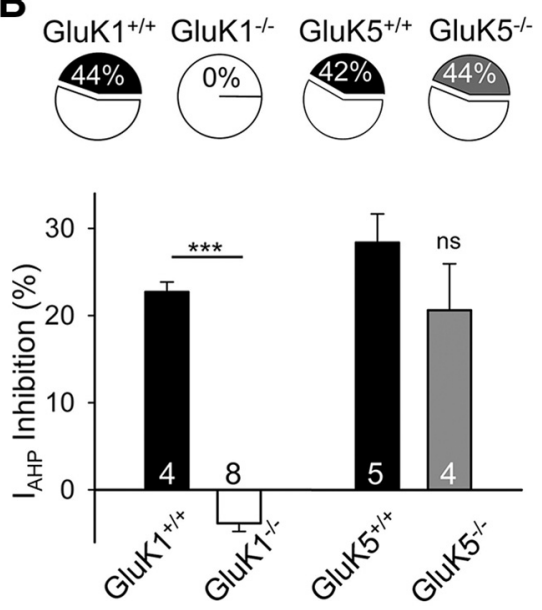

Figure 5. Deletion of GluK1 but not GluK5 prevents noncanonical signaling of kainate receptors. $\boldsymbol{A}$, application of kainate (100 $\mathrm{nM}$ ) reduces the peak $I_{\text {AHP }}$ amplitude in wild-type DRG neurons but not in those dissociated from GluK1 ${ }^{-/-}$mice. Sample traces (top) before (black) and after (gray) application of kainate. Bottom, Time course of kainate-evoked inhibition in neurons from control (black) and GluK1 ${ }^{-1-}$ mice (open symbols). B, Proportion of cells in which inhibition was observed in several experimental conditions (top) and the inhibition in neurons from GluK1 and GluK5 wild-type and deficient mice. Numbers within bars are the number of studied neurons. ${ }^{* * *} p<0.001$ (Student's $t$ test).

in cell-cycle and growth control, signal transduction, and apoptosis (van Hemert et al., 2001), although the precise role of the association between 14-3-3 proteins and distinct GluK subunits remains unclear (Coussen et al., 2005; Vivithanaporn et al., 2006). However, some 14-3-3 protein isoforms are proposed to act as chaperones in KAR trafficking (Coussen et al., 2005) and they could drive the interactions between distinct subunits that are involved in the biosynthesis of heteromeric KARs (Vivithanaporn et al., 2006). Protein 4.1 has been also identified as an interactor of GluK2 in a recent proteomic analysis of AMPARs and KARs (Shanks et al., 2012) and thus further studies will be necessary to define the role of these proteins in KAR biology.

Some of the other proteins identified were not previously known to interact with KARs, opening the possibility that novel pathways regulate KARs. For instance, CaMKII phosphorylates several types of glutamate receptors, including KARs, and although the possibility that it phosphorylates GluK1 cannot be discarded (particularly since GluK1 $1_{\mathrm{b}}$ contains three consensus sites for CaMKII phosphorylation; White et al., 1998), the interaction with GluK1 would bring this kinase in close proximity to GluK5 subunits in naturally occurring heteromeric GluK1GluK5 receptors. Activation of CaMKII induces long-term depression of synaptic transmission at the hippocampal mossy fiber synapse upon phosphorylation of GluK5 subunits (Carta et al., 2013), which may be favored by the existence of such a complex. Although it is difficult to figure out the role of other interactions, it is worth noting that our study revealed the interaction of GluK1 with Basp1, a cytoskeleton-associated protein that binds calmodulin and is abundantly expressed during brain development and reinduced during nerve regeneration (Frey et al., 2000). Together with GAP43, another new GluK1-interacting protein, Basp1 plays a critical role in regulating neuritic outgrowth. Indeed Basp 1 can functionally substitute for GAP-43 in vivo (Frey et al., 2000). It remains to be demonstrated whether the recent role ascribed to KARs in neurite elongation (Marques et al., 2013) is related to the interactions with these two proteins. Two more GluK1 interactors are Rab3a and synapsin II. Both proteins are present presynaptically in most synapses and play key roles in synaptic vesicle trafficking and transmitter release. It is known

that KARs are able to regulate glutamate and GABA release acting presynaptically, but it would be premature to think of this novel interaction as a mechanism involved in this phenomenon. Whatever the roles, if any, of these interactions, it is important to recognize that the proteomic approach followed in this and other studies allows proteins to make contact that might never occur in vivo because they would function in different places.

One of the proteins identified was a G-protein $\alpha$ subunit and indeed KARs have been postulated to interact with G-proteins as some of their effects are abolished in the presence of pertussis toxin (Rodríguez-Moreno and Lerma, 1998; Cunha et al., 2000; RodríguezMoreno et al., 2000; Melyan et al., 2002; Rozas et al., 2003). However, there was no evidence yet of a direct interaction between these two proteins. It is believed that KARs could operate in two different modes: the well characterized and expected ionotropic action; and by G-protein activation, which regulates different effectors, including other ion channels. Yet, we still do not have clear understanding of this latter mode of action, the so-called noncanonical signaling (Rozas et al., 2003), nor the class of KAR subunit that interacts with G-proteins. Our data evidence that the GluK1 subunit, in particular the $\mathrm{GluK} 1_{\mathrm{b}}$ isoform that contains the longer $\mathrm{C}$ terminus, may represent the link to the G-protein $\alpha$ subunit. Although an interaction between GluK5 and $\mathrm{Gq}$ proteins has been suggested to account for metabotropic activity of KARs (Ruiz et al., 2005), present data and functional evidence from different analyses of noncanonical signaling contradict this idea. First, the metabotropic activity mediated by KARs indicates the involvement of a pertussis-sensitive G-protein that can signal through PLC. For instance, G-proteinmediated inhibition of $\mathrm{N}$-type $\mathrm{Ca}^{2+}$ channels in DRG neurons takes place under conditions not requiring ion permeation through the KAR channel and it is abolished upon exposure to pertussis toxin (Rozas et al., 2003). KARs also inhibit the slow afterhyperpolarization (sAHP) generated by a voltage-independent, $\mathrm{Ca}^{2+}$-dependent $\mathrm{K}^{+}$current $\left(I_{\mathrm{AHP}}\right.$; Fisahn, 2005; Fisahn et al., 2004; Melyan et al., 2002, 2004), resulting in the enhancement of pyramidal cell excitability, which can be prevented by intracellular pertussis toxin (Grabauskas et al., 2007). KAR-mediated inhibition of neurotransmitter release in several areas of the brain is also sensitive to this toxin (Rodríguez-Moreno and Lerma, 1998; Jin et al., 2006) and thus the evidence available indicates that KARs activate a second messenger cascade of which the first element in the chain is a $\mathrm{G} \alpha$ o protein. Actually, $\mathrm{G} \alpha$ o proteins are the only known G-proteins linked to PLC that activate PKC and that, unlike $\mathrm{G} \alpha \mathrm{q}$, which activates a similar cascade, is sensitive to pertussis toxin. Moreover, our results using KO mice indicate that GluK1 rather than GluK5 is required to trigger G-protein activation in DRG neurons (Fig. 5). Also, data show that metabotropic signaling remained in GluK4/GluK5 double-KO mice (Fernandes et al., 2009). Similarly, recent experiments suggested the involvement of GluK1 in the metabotropic control of glutamate release (Segerstråle et al., 2010; Salmen et al., 2012). Therefore, our data clarify that the KAR subunit capable of activating a G-protein is GluK $1_{b}$ and that this G-protein corresponds to the G $\alpha$ o type, 
which is consistent with earlier indirect data showing that GluK1 subunits can reproduce noncanonical KAR signaling in a heterologous system (Rivera et al., 2007). Although it is possible that different KAR subunits interact with multiple types of G-proteins, these data indicate that GluK1 is necessary and sufficient to trigger noncanonical signaling by KARs.

It still remains to be ascertained whether the GluK1-G $\alpha$ o interaction is direct or not. Ionotropic and metabotropic glutamate receptors differ profoundly in their structure, making it unlikely that G-protein activation by either receptor upon glutamate binding follows a similar mechanism. A crystal structure of KAR intracellular domains would help explain how this occurs. Unfortunately, no such structure is available. However, several indications advocate for a direct interaction between GluK1 and G $\alpha$ o protein. First, GluK1 coimmunoprecipitates with $\mathrm{G} \alpha$ o proteins when cells coexpress both proteins. Second, an interaction between these proteins can be detected by BiFC when they are both expressed in HEK cells. In addition, noncanonical signaling is reconstituted in HEK cells by expressing both proteins, as indicated by BRET data. Together, these results lead us to propose that GluK1 and G $\alpha$ o form part of a specific protein complex and that they interact with one another without the need for additional proteins.

Noncanonical KAR signaling has been implicated in a number of fundamental processes, altering the equilibrium between excitation and inhibition in the nervous system, upon which correct brain performance ultimately depends. Therefore, our data provide clues for the development of drugs able to discriminate between both signaling systems, further improving our capacity to finely modulate brain activity.

\section{References}

Ayoub MA, Couturier C, Lucas-Meunier E, Angers S, Fossier P, Bouvier M, Jockers R (2002) Monitoring of ligand-independent dimerization and ligand-induced conformational changes of melatonin receptors in living cells by bioluminescence resonance energy transfer. J Biol Chem 277: 21522-21528. CrossRef Medline

Ayoub MA, Damian M, Gespach C, Ferrandis E, Lavergne O, De Wever O, Banères JL, Pin JP, Prévost GP (2009) Inhibition of heterotrimeric G protein signaling by a small molecule acting on Galpha subunit. J Biol Chem 284:29136-29145. CrossRef Medline

Carta M, Opazo P, Veran J, Athané A, Choquet D, Coussen F, Mulle C (2013) CaMKII-dependent phosphorylation of GluK5 mediates plasticity of kainate receptors. EMBO J 32:496-510. CrossRef Medline

Copits BA, Swanson GT (2013) Kainate receptor post-translational modifications differentially regulate association with $4.1 \mathrm{~N}$ to control activitydependent receptor endocytosis. J Biol Chem 288:8952-8965. CrossRef Medline

Coussen F, Mulle C (2006) Kainate receptor-interacting proteins and membrane trafficking. Biochem Soc Trans 34:927-930. CrossRef Medline

Coussen F, Perrais D, Jaskolski F, Sachidhanandam S, Normand E, Bockaert J, Marin P, Mulle C (2005) Co-assembly of two GluR6 kainate receptor splice variants within a functional protein complex. Neuron 47:555-566. CrossRef Medline

Cunha RA, Malva JO, Ribeiro JA (1999) Kainate receptors coupled to G(i)/ $\mathrm{G}(\mathrm{o})$ proteins in the rat hippocampus. Mol Pharmacol 56:429-433. Medline

Cunha RA, Malva JO, Ribeiro JA (2000) Pertussis toxin prevents presynaptic inhibition by kainate receptors of rat hippocampal [(3)H]GABA release. FEBS Lett 469:159-162. CrossRef Medline

Fernandes HB, Catches JS, Petralia RS, Copits BA, Xu J, Russell TA, Swanson GT, Contractor A (2009) High-affinity kainate receptor subunits are necessary for ionotropic but not metabotropic signaling. Neuron 63:818829. CrossRef Medline

Fisahn A (2005) Kainate receptors and rhythmic activity in neuronal networks: hippocampal gamma oscillations as a tool. J Physiol 562:65-72. CrossRef Medline

Fisahn A, Contractor A, Traub RD, Buhl EH, Heinemann SF, McBain CJ
(2004) Distinct roles for the kainate receptor subunits GluR5 and GluR6 in kainate-induced hippocampal gamma oscillations. J Neurosci 24: 9658-9668. CrossRef Medline

Frey D, Laux T, Xu L, Schneider C, Caroni P (2000) Shared and unique roles of CAP23 and GAP43 in actin regulation, neurite outgrowth, and anatomical plasticity. J Cell Biol 149:1443-1454. CrossRef Medline

Grabauskas G, Lancaster B, O'Connor V, Wheal HV (2007) Protein kinase signalling requirements for metabotropic action of kainate receptors in rat CA1 pyramidal neurones. J Physiol 579:363-373. CrossRef Medline

Gray EG, Whittaker VP (1962) The isolation of nerve endings from brain: an electron-microscopic study of cell fragments derived by homogenization and centrifugation. J Anat 96:79-88. Medline

Hirbec H, Francis JC, Lauri SE, Braithwaite SP, Coussen F, Mulle C, Dev KK, Coutinho V, Meyer G, Isaac JT, Collingridge GL, Henley JM, CouthinoV (2003) Rapid and differential regulation of AMPA and kainate receptors at hippocampal mossy fibre synapses by PICK1 and GRIP. Neuron 37: 625-638. CrossRef Medline

Janetopoulos C, Jin T, Devreotes P (2001) Receptor-mediated activation of heterotrimeric G-proteins in living cells. Science 291:2408-2411. CrossRef Medline

Jin XT, Paré JF, Raju DV, Smith Y (2006) Localization and function of preand postsynaptic kainate receptors in the rat globus pallidus. Eur J Neurosci 23:374-386. CrossRef Medline

Kerppola TK (2006) Design and implementation of bimolecular fluorescence complementation (BiFC) assays for the visualization of protein interactions in living cells. Nat Protoc 1:1278-1286. CrossRef Medline

Lerma J (2003) Roles and rules of kainate receptors in synaptic transmission. Nat Rev Neurosci 4:481-495. CrossRef Medline

Lerma J, Marques JM (2013) Kainate receptors in health and disease. Neuron 80:292-311. CrossRef Medline

Link AJ, Eng J, Schieltz DM, Carmack E, Mize GJ, Morris DR, Garvik BM, Yates JR 3rd (1999) Direct analysis of protein complexes using mass spectrometry. Nat Biotechnol 17:676-682. CrossRef Medline

Marques JM, Rodrigues RJ, Valbuena S, Rozas JL, Selak S, Marin P, Aller MI, Lerma J (2013) CRMP2 tethers kainate receptor activity to cytoskeleton dynamics during neuronal maturation. J Neurosci 33:18298-18310. CrossRef Medline

Martin S, Nishimune A, Mellor JR, Henley JM (2007) SUMOylation regulates kainate-receptor-mediated synaptic transmission. Nature 447:321325. CrossRef Medline

Melyan Z, Wheal HV, Lancaster B (2002) Metabotropic-mediated kainate receptor regulation of IsAHP and excitability in pyramidal cells. Neuron 34:107-114. CrossRef Medline

Melyan Z, Lancaster B, Wheal HV (2004) Metabotropic regulation of intrinsic excitability by synaptic activation of kainate receptors. J Neurosci 24:4530-4534. CrossRef Medline

Nabavi S, Kessels HW, Alfonso S, Aow J, Fox R, Malinow R (2013) Metabotropic NMDA receptor function is required for NMDA receptor-dependent long-term depression. Proc Natl Acad Sci U S A 110:4027-4032. CrossRef Medline

Palacios-Filardo J, Aller MI, Lerma J (2014) Synaptic targeting of kainate receptors. Cereb Cortex, pii:bhu24410.1093. Advance online publication. Retrieved Feb. 24, 2015. Medline

Perkins DN, Pappin DJ, Creasy DM, Cottrell JS (1999) Probability based protein identification by searching sequence databases using mass spectrometry data. Electrophoresis 20:3551-3567. CrossRef Medline

Rivera R, Rozas JL, Lerma J (2007) PKC-dependent autoregulation of membrane kainate receptors. EMBO J 26:4359-4367. CrossRef Medline

Rodríguez-Moreno A, Lerma J (1998) Kainate receptor modulation of GABA release involves a metabotropic function. Neuron 20:1211-1218. CrossRef Medline

Rodríguez-Moreno A, López-García JC, Lerma J (2000) Two populations of kainate receptors with separate signaling mechanisms in hippocampal interneurons. Proc Natl Acad Sci U S A 97:1293-1298. CrossRef Medline

Rozas JL, Paternain AV, Lerma J (2003) Noncanonical signaling by ionotropic kainate receptors. Neuron 39:543-553. CrossRef Medline

Ruiz A, Sachidhanandam S, Utvik JK, Coussen F, Mulle C (2005) Distinct subunits in heteromeric kainate receptors mediate ionotropic and metabotropic function at hippocampal mossy fiber synapses. J Neurosci 25:11710-11718. CrossRef Medline

Saka Y, Hagemann AI, Piepenburg O, Smith JC (2007) Nuclear accumula- 
tion of Smad complexes occurs only after the midblastula transition in Xenopus. Development 134:4209-4218. CrossRef Medline

Salmen B, Beed PS, Özdogan T, Maier N, Johenning FW, Winterer J, Breustedt J, Schmitz D (2012) GluK1 inhibits calcium dependent and independent transmitter release at associational/commissural synapses in area CA3 of the hippocampus. Hippocampus 22:57-68. CrossRef Medline

Segerstråle M, Juuri J, Lanore F, Piepponen P, Lauri SE, Mulle M, Taira T (2010) High firing rate of neonatal hippocampal interneurons is caused by attenuation of afterhyperpolarizing potassium currents by tonically active kainate receptors. J Neurosci 30:6507-6514. CrossRef Medline

Selak S, Paternain AV, Aller IM, Picó E, Rivera R, Lerma J (2009) A role for SNAP25 in internalization of kainate receptors and synaptic plasticity. Neuron 63:357-371. CrossRef Medline

Shanks NF, Savas JN, Maruo T, Cais O, Hirao A, Oe S, Ghosh A, Noda Y, Greger IH, Yates JR 3rd, Nakagawa T (2012) Differences in AMPA and Kainate Receptor Interactomes Facilitate Identification of AMPA Receptor Auxiliary Subunit GSG1L. Cell Reports 1:590-598. CrossRef Medline

Sommer B, Burnashev N, Verdoorn TA, Keinänen K, Sakmann B, Seeburg PH (1992) A glutamate receptor channel with high affinity for domoate and kainate. EMBO J 11:1651-1656. Medline

Tomita S, Castillo PE (2012) Neto1 and Neto2: auxiliary subunits that de- termine key properties of native kainate receptors. J Physiol 590:22172223. CrossRef Medline

van Hemert MJ, Steensma HY, van Heusden GP (2001) 14-3-3 proteins: key regulators of cell division, signalling and apoptosis. Bioessays 23:936946. CrossRef Medline

Vivithanaporn P, Yan S, Swanson GT (2006) Intracellular trafficking of KA2 kainate receptors mediated by interactions with coatomer protein complex I (COPI) and 14-3-3 chaperone systems. J Biol Chem 281:1547515484. CrossRef Medline

Wang Y, Small DL, Stanimirovic DB, Morley P, Durkin JP (1997) AMPA receptor-mediated regulation of a Gi-protein in cortical neurons. Nature 389:502-504. CrossRef Medline

White RR, Kwon YG, Taing M, Lawrence DS, Edelman AM (1998) Definition of optimal substrate recognition motifs of $\mathrm{Ca} 2+$-calmodulindependent protein kinases IV and II reveals shared and distinctive features. J Biol Chem 273:3166-3172. CrossRef Medline

Wilkinson KA, Nishimune A, Henley JM (2008) Analysis of SUMO-1 modification of neuronal proteins containing consensus SUMOylation motifs. Neurosci Lett 436:239-244. CrossRef Medline

Yi TM, Kitano H, Simon MI (2003) A quantitative characterization of the yeast heterotrimeric G protein cycle. Proc Natl Acad Sci U S A 100: 10764-10769. CrossRef Medline 